\title{
Confrontando a norma: modos de participação de crianças com Transtorno do Espectro do Autismo na escola
}

\author{
Adriana Lia Friszman de Laplane*
}

\begin{abstract}
Resumo
A perspectiva histórico-cultural oferece ferramentas conceituais e analíticas para a compreensão das relações que se estabelecem entre os sujeitos que participam das dinâmicas sociais e institucionais. Tomando como pontos de partida as reflexões vigotskianas sobre o papel constitutivo da cultura e das relações sociais no desenvolvimento e na aprendizagem, o presente artigo explora o potencial dessas ferramentas para a análise das formas de participação de crianças com Transtorno do Espectro do Autismo na escola e amplia a discussão para abordar a normatividade das instituições de saúde e de educação e para as práticas de patologização, comuns hoje no âmbito educacional.

Palavras-chave: Desenvolvimento cultural; Autismo; Inclusão.
\end{abstract}

\section{Confronting the norm: modes of participation of children with ASD at school}

\begin{abstract}
The historical-cultural perspective offers conceptual and analytical tools to the understanding of the relationships established between individuals that participate of the social and institutional dynamics. Taking as points of departure the vigotskian reflections on the constitutive role of culture and social relations in development and learning, this article explores the potential of these tools for the analysis of the forms of participation of children with autism spectrum disorder in school and broadens the discussion to approaching the norm oriented tendency of health and education institutions and to the pathologizing practices, common today in the educational sphere.

Keywords: Cultural development; Autism; Inclusion.
\end{abstract}

\section{S. Vigotski: desenvolvimento e deficiência}

L. S. Vigotski ${ }^{1}$ nos legou a inspiradora ideia de que o desenvolvimento é um processo essencialmente cultural, que envolve a mediação da linguagem e do outro. À época em que formulou a sua teoria e elaborou os conceitos necessários para a sua compreensão, o autor se contrapôs às visões estritamente biológicas e comportamentais, assim como às subjetivistas. A concepção do desenvolvimento humano como processo fortemente alicerçado na cultura e na experiência social propiciou a reflexão sobre o entrelaçamento dessas dimensões com os aspectos biológicos e neuropsicológicos. Esse movimento redimensionou o entendimento do papel das relações entre o desenvolvimento do indivíduo e sua interação com o ambiente social. Vigotski encontrou na linguagem, a chave para desvendar o modo como a cultura se torna parte integrante da percepção, da atenção, da memória e do pensamento; dos percursos do desenvolvimento e da aprendizagem. Por isso, nos seus estudos sobre o desenvolvimento e a aprendizagem de crianças com deficiência destacamse, a linguagem, o sentido e a significação como meios de desenvolvimento cultural.
No texto "La infancia difícil", que compõe o volume "Fundamentos de Defectología", Vigotski (1997) afirma a necessidade de compreender as causas que motivam as dificuldades e de combater a origem do que chama "traços negativos do caráter" (p. 158). O texto escrito em 1928 aborda o problema da criança dificilmente educável, genericamente entendida como aquela que não se adequa às normas, não leva em consideração o outro ou reage de modo impulsivo, agressivo ou mesmo afastando-se da realidade. Ela pode ser ou não especialmente talentosa, pode ser ou não capaz de aprender alguns tipos de conhecimento, pode apresentar problemas motores e/ou cognitivos, mas, de acordo com o ponto de vista do autor, sempre é possível partir das capacidades que a criança possui e prestar atenção às formas em que elas se integram para permitir a realização das diferentes atividades que a vida social demanda.

Chama a nossa atenção, nesse texto, a coincidência da descrição das dificuldades de desenvolvimento com o que a Associação Psiquiátrica Americana (APA) convenciona chamar Transtorno do Espectro do Autismo (APA, 2014). A classificação é largamente utilizada no nosso meio, para diagnóstico, tratamento e oferta de recursos 
terapêuticos e de educação especial. Por outro lado, é digna de nota, no texto de Vigotski, a rejeição das descrições de sintomas isolados, tomados como entidades em si, que não levam em consideração os recursos psicológicos do sujeito, a sua história e as suas relações com o meio, como pontos de partida legítimos para a teoria, a clínica ou a ação educativa.

Ainda, no texto intitulado "El desarrollo del niño difícil y su estudio" (VIGOTSKI, 1997) quando aborda novamente o tema das crianças dificilmente educáveis, o autor destaca que na maior parte dos casos, a origem dos problemas é um conflito psicológico entre a criança e o meio e reconhece a importância do inconsciente e da necessidade de utilizar métodos de estudo que permitam aproximarse a esses aspectos mais profundos da subjetividade.

Da mesma forma, Vigotski adere às criticas de diversos psicólogos da sua época à concepção inglesa que, sob o rótulo de Moral Insanity, agrupava crianças abandonadas, delinquentes ou consideradas não educáveis. Os alegados defeitos morais eram concebidos como manifestações de uma doença orgânica. Ainda, ele elenca os argumentos que destacam o papel das relações com o meio social e das condições da existência no desenvolvimento da criança.

A partir da ideia de que o desenvolvimento é um processo único e singular, Vigotski advoga, em outro dos seus escritos, em favor da necessidade de encontrar caminhos alternativos, não previstos ou pouco usuais na cultura que supõe o desenvolvimento típico. Ao se referir à criança cega ou surda, por exemplo, ele afirma: "Os cegos e os surdos-mudos são como um experimento natural que demonstra que o desenvolvimento cultural do comportamento não se relaciona, necessariamente, com essa ou aquela função orgânica". (VIGOTSKI, 2011 p. 868).

Mas, então, com o que se relaciona? O início do texto (escrito entre 1924 e 1931) aponta para a direção das suas reflexões: "Atualmente, a questão consiste em romper o aprisionamento biológico da psicologia e passar para o campo da psicologia histórica, humana". (VIGOTSKI, 2011, p. 864).

Essas reflexões são ainda hoje, muito pertinentes. O Atualmente da década de 1920 pode facilmente ser transposto para o presente século XXI. Diferentemente das correntes organicistas e comportamentais vigentes no seu tempo e hegemônicas em muitos contextos até hoje, Vigotski propõe um olhar materialista, histórico e dialético, que além de integrar o biológico, o psicológico, o cultural e o afetivo, preserva o caráter complexo do processo de desenvolvimento. Essa concepção dinâmica visa à compreensão das formas de constituição de um sujeito em permanente movimento, afetado pelas condições da existência material. O processo é balizado pelas formas peculiares assumidas pela síntese individual, dependente da vivência de cada sujeito.

Assim sendo, somos instados a conceber a deficiência como mais um entre os múltiplos processos e experiências que participam na constituição da subjetividade. É importante destacar que embora a deficiência (ou a vivência da deficiência) possa marcar fortemente a vida, ela não é em si impeditiva do desenvolvimento, da aprendizagem ou da participação social. Ao contrário, Vigotski argumenta em favor da unidade dos processos psicológicos, os quais, em termos gerais, são basicamente iguais para todos os seres humanos, ainda que envolvam caminhos singulares e mesmo peculiares (VIGOTSKI, 1997). Afasta-se assim das visões que enfocam a natureza biológica do defeito. Como mostra Dainez (2014) em seu estudo sobre o conceito de compensação, o pensamento de Vigotski é crítico em relação ao foco das teorias em voga na época: a correção e a normalização. As críticas recaem sobre a compreensão da compensação como mecanismo biológico ou contrapartida social cuja função é suprir aquilo que falta ao sujeito. Vigotski aponta para uma visão que se contrapõe claramente a estas quando afirma que a educação deve investir no potencial de desenvolvimento e na promoção da participação do sujeito nas práticas sociais (DAINEZ, 2014; DAINEZ; SMOLKA, 2016).

Contudo, ao considerar a história e as práticas que o conceito sustentou, é preciso reconhecer que apesar dos esforços de Vigotski e dos pesquisadores adeptos à perspectiva históricocultural que conviveram com ele e o sucederam, os sentidos relacionados ao biológico e ao individual prevaleceram, tanto no campo da psicologia como no da educação, e não apenas no que se refere ao conceito de compensação, mas também no que diz respeito às concepções sobre desenvolvimento e deficiência, de modo geral. Os avanços tecnológicos aplicados a uma neurociência que muitas vezes prescinde de teorias de desenvolvimento humano e baseia as suas hipóteses em características anatômicas, cognitivas ou genéticas, por exemplo, tem parte no processo de legitimação das visões biológicas. Esse movimento, recorrente na história da psicologia e da educação, gera um efeito reducionista compatível com os sentidos, também 
dominantes, da correção e da normalização. Entre as suas consequências podemos mencionar a prescrição de práticas supostamente apropriadas para cada tipo de deficiência.

As ideias de Vigotski tornam compreensível a longevidade dessas tendências. Elas colaboram, também, para pensar práticas compatíveis com uma concepção de desenvolvimento que engloba os aspectos biológicos, as condições da existência, as possibilidades de participação social, os modos próprios e singulares de elaborar as vivências e de construir a subjetividade mediada pela linguagem no contexto das relações sociais e da interação permeada pela afetividade, e que, por fim, não prescinde das dimensões inconscientes (VIGOTSKI, 1997). Não se trata, assim, de negar que a biologia participa dos processos de desenvolvimento, mas de integrar esses achados no quadro conceitual da perspectiva histórico-cultural, destacando a importância das condições materiais, culturais, afetivas e subjetivas para o desenvolvimento humano.

Além disso, essa perspectiva inspira a reflexão sobre o caráter autocentrado (centrado na norma) das visões que opõem normalidade e deficiência, concentrando em diversas instâncias sociais, como as instituições de saúde e de educação, o poder de ditar os objetivos do desenvolvimento e os caminhos (terapêuticos, medicamentosos ou educacionais) para atingi-los. Nesse sentido, os debates conceituais antes referidos, empreendidos nos âmbitos da psicologia e da educação na primeira metade do século $\mathrm{XX}$ não são privativos desses campos de conhecimento. Também a filosofia aporta as suas considerações ao discutir as relações entre o normal e o patológico. A discussão que opõe ambos os termos remonta à Antiguidade e ganha visibilidade no século $\mathrm{XX}$, quando abordada por filósofos como Georges Canguilhem e Michel Foucault. Assim como os conceitos cunhados por Vigotski, as ideias de ambos os autores serão relevantes para pensar as concepções de normalidade e patologia vigentes e as suas implicações para as práticas escolares e para a participação de crianças com TEA na escola.

\section{O normal e o patológico: modos de situar a diferença}

Canguilhem é autor de um famoso trabalho, a sua tese de doutoramento, escrita em 1943, que examinou as relações histórico-filosóficas entre os conceitos de normal e patológico. À ideia vigente na tradição positivista dominante à época, de que o normal e o patológico seriam definidos por mudanças quantitativas, Canguilhem opôs uma visão dinâmica, que ponderava as relações entre ambos os tipos de fenômeno e as condições da vida social, as quais definiriam normas e padrões, além das condições individuais, sujeitas a grande variabilidade (CANGUILHEM, 2009).

$\mathrm{Na}$ sua tese, Canguilhem discorre sobre os estados de saúde e doença e sobre as relações entre eles. A cura não significa o retorno a um estado de saúde prévio, mas, a presença de novas normas de vida, diferentes das anteriores. Pensa, assim, a normalidade e a patologia como conceitos estreitamente relacionados, não apenas entre si, mas também como qualidades dos modos de viver dos sujeitos nas condições proporcionadas pelo meio (social, cultural, físico).

A tese influenciou notavelmente a filosofia da ciência tanto na França como em outros países do mundo ocidental e provocou inúmeros debates sobre os conceitos de normalidade e patologia, continuidade e ruptura, quantidade e qualidade, entre outros. Esses debates se estenderam pelo século XX, adentraram o século XXI e ainda hoje geram discussão.

A historiadora e psicanalista Elizabeth Roudinesco (2007) comenta a inspiração biográfica dos questionamentos levantados por Canguilhem, quem reflete sobre esses conceitos em um momento particular da história, marcado pela guerra e pela invasão da Europa e da França pela Alemanha comandada por Hitler. Canguilhem, nesse momento, participava da Resistência francesa e a guerra foi o período em que levou adiante a sua principal experiência de atuação no campo da medicina. Roudinesco nota que a Resistência “... funcionou, para ele, como o paradigma de uma descontinuidade na ordem da normatividade, ou seja, como o momento da adoção de uma nova norma, surgida da vida". (ROUDINESCO, 2007, p. 29) A autora pergunta: o que era normal em 1940? A submissão à ordem, aceita por praticamente todo o povo ou a escolha de outra norma, que rompe com a aparência de normalidade?

A análise conceitual, o exame rigoroso das posições de filósofos, sociólogos, fisiologistas e médicos parecem alheios à vida fora da academia, regulada pela ação política e pela prática médica em situação de urgência. Entretanto, a tese sobre a derrocada da norma e a problematização dos conceitos de normal e patológico podem ser vistos também como parte de uma mesma perspectiva, que engloba a vida clandestina da resistência à ocupação 
nazista e o engajamento em ações de oposição à opressão, na medida em que seu trabalho argumenta em favor de pontos de vista que questionam o estabelecido.

O pensamento de outro filósofo provoca de forma mais radical ainda o questionamento sobre o modo como a sociedade impõe o normal e a norma, forjando a subjetividade nos espaços sociais. Michel Foucault também escreveu uma tese de doutorado que ficou famosa e da qual G. Canguilhem foi relator. É interessante registrar que após a leitura da obra de Foucault, Canguilhem modificou seu próprio trabalho, abandonando parcialmente o vitalismo e enfatizando a ideia de uma normatividade ancorada na existência e nas práticas sociais. Convém também resgatar a sua crítica à psicologia, disciplina que em sua vertente comportamental e adaptativa considerava como uma escola de submissão, aniquiladora da liberdade (ROUDINESCO, 2007).

De maneira singular, no trabalho defendido em 1961, o autor propôs um novo modo de definir a norma como construção histórica (FOUCAULT, 1997). Ao comparar Canguilhem com Foucault, Roudinesco afirma que:

Foucault substituía a concepção de Canguilhem de uma norma produzida pela vida pela ideia de uma norma construída pela ordem social e portadora de normalização. Opunha, assim, uma normatividade social a uma normatividade biológica, uma arqueologia a uma fenomenologia. (ROUDINESCO, 2007, p. 44)

A questão é recorrente e formulada de diversas maneiras na obra do Foucault. No seu primeiro livro, escrito em 1954 e depois revisto, questiona as comparações entre os fenômenos da patologia mental e orgânica. No mesmo livro retoma uma ideia que alega ser "... lugar comum da sociologia e da patologia mental: a doença só tem realidade e valor de doença no interior de uma cultura que a reconhece como tal". (FOUCAULT, 1988, p.71).

Em outra das suas obras, escrita em meados da década de 70, Foucault (1987) lança seu olhar crítico sobre a sociedade ocidental, ao analisar os efeitos de práticas disciplinadoras em espaços como prisões, hospitais, escolas e fábricas, em que as relações de poder se manifestam mesmo (ou principalmente) nas minúcias. A análise chama a atenção para aspectos tais como: a organização do espaço e dos processos de trabalho, a regulação da comunicação entre as pessoas, a sua distribuição nos espaços em função da vigilância e do controle das ações e das manifestações.

As formas de organização escolar dizem muito sobre a sociedade disciplinadora. Foucault nos remete aos colégios jesuítas, que seguiam o modelo das legiões romanas e promoviam exercícios de rivalidade entre classes organizadas de modo vertical e hierárquico. $\mathrm{O}$ ensino seriado origina grandes modificações ao estabelecer práticas e sequências, tempos e tipos de atividade:

Determinando lugares individuais tornou
possível o controle de cada um e o trabalho
simultâneo de todos. Organizou uma nova
economia do tempo de aprendizagem. Fez
funcionar o espaço escolar como uma máquina de
ensinar, mas também de vigiar, de hierarquizar,
de recompensar. (FOUCAULT, 1987, p. 173)

Vislumbra-se, nas práticas do século XVIII, a instalação de um tipo de disciplina que visa a organizar, classificar e controlar a vida material, corporal, intelectual e psíquica. $\mathrm{O}$ aumento da população, a sua concentração nas cidades e as novas formas de produção capitalista requerem sujeitos forjados na disciplina e as práticas de educação refletem as novas demandas da sociedade.

Ainda, nas suas aulas no Collège de France, Foucault faz menção à sociedade normalizadora, em que o poder é exercido por meio das técnicas da disciplina e do direito, amplificados pelo desenvolvimento da medicina. $\mathrm{O}$ resultado disso é a medicalização do comportamento (FOUCAULT, 2005).

A essas ideias, elaboradas na década de 1970, podemos acrescentar outros elementos que atuam na contemporaneidade no sentido de potencializar a tendência à normalização: o desenvolvimento da tecnologia aplicada à saúde, principalmente na área das neurociências, o desenvolvimento de medicamentos e drogas e a ampliação do poder dos discursos médico e científico, os quais legitimam prescrições medicamentosas, educacionais e comportamentais que lhes permitem exercer autoridade sobre diversas esferas da vida dos sujeitos.

\section{Condições e possibilidades para a criança com TEA na cena escolar}

Pouco foi dito, até aqui, especificamente sobre a criança com TEA e sobre a escola. Preferimos apresentar algumas das ideias em que se ancoram as análises das concepções e práticas vigentes. Falamos sobre desenvolvimento, cultura, criança com 
deficiência, normal e patológico e disciplina.

A perspectiva histórico-cultural nos oferece um interessante arcabouço teórico para entender o desenvolvimento da criança e o papel da escola nesse processo.

Levar em consideração as premissas vigotskianas implica dirigir a atenção para as formas de organização e funcionamento da escola. Os filósofos Canguilhem e Foucault auxiliam na realização dessa tarefa. Os dispositivos responsáveis por dar à instituição a sua configuração própria, assim como as práticas pedagógicas vigentes, atendem, na maioria das instituições educativas, aos critérios normativos que envolvem desde os modos de organização do espaço e a disposição das pessoas até a transmissão de valores e conhecimentos. Estes se traduzem em competências, aprendizagens e comportamentos valorados positivamente que se contrapõem a comportamentos e aprendizagens não desejados. Não basta a criança aprender. Ela deverá aprender o que é ensinado, sentada, calada, sozinha e de forma ordenada, mesmo que o ambiente seja compartilhado com outras trinta ou mais crianças; deverá ser organizada e também mostrar "boas maneiras"; aprender a lidar com a frustração, a adiar os seus desejos e necessidades e a aceitar as regras de convivência e de obediência, a responder perguntas e realizar provas e exames, a participar, enfim, do modo convencional e esperado.

Apesar de que isso parece hoje indispensável para a participação escolar e o bom desempenho acadêmico, uma parcela significativa dos alunos está fadada a não conseguir se adequar a essas exigências. Entre as crianças que fracassam, algumas provêm de comunidades, grupos ou famílias em que as práticas culturais se afastam daquelas valorizadas pela escola. O sociólogo francês Pierre Bourdieu (1998, 2002) estudou esse modo de funcionamento da instituição escolar e descreveu a dinâmica que colabora para criar mecanismos de exclusão social no seu interior. As conclusões das suas pesquisas, realizadas na década de 1960 na França, ainda descrevem acuradamente as formas de funcionamento da escola e são úteis na análise do contexto brasileiro atual. Bourdieu alerta para a distância, às vezes intransponível, entre a cultura da instituição e a dos alunos. Os usos da linguagem são distantes da norma culta, os modos e maneiras, diferentes dos usuais na escola. Essas diferenças são muitas vezes inconscientes e apagadas por dinâmicas de funcionamento que igualam todas as crianças, considerando que ao chegar à escola, todas partem do mesmo ponto. Deste modo, torna-se difícil a construção conjunta (escola e alunos) de um espaço simbólico em que o conhecimento possa ser compartilhado, devido à dificuldade de se estabelecer referências comuns. Em consequência, muitas crianças custam a se inserir nas práticas escolares e a manter o ritmo imposto pelos objetivos para cada série e grau, pelos currículos, programas e atividades.

Além daquelas que fracassam devido às suas origens socioeconômicas ou culturais e a pouca familiaridade com os estilos, linguagem e práticas escolares, as crianças com deficiência e as crianças com TEA geram grandes problemas para as escolas. Estas últimas, em particular, desafiam, justamente, as normas de comportamento, os modos de aprender e de se comunicar convencionais, sobre os quais se assentam, de forma explícita ou tácita, as políticas e práticas de educação.

Embora a variabilidade entre as crianças diagnosticadas com o transtorno seja grande (algumas falam e outras não, algumas podem apresentar desatenção, agitação e/ou impulsividade ou quietude e isolamento, dificuldades para se relacionar e comunicar com outras crianças e adultos, dificuldades mais ou menos severas de aprendizagem, recusa em participar das atividades ou realizar tarefas, ter interesses restritos e dificuldades para aceitar mudanças, entre outras características), as queixas escolares são muitas, já que a organização seriada da escola pressupõe a homogeneidade. A instituição escolar tem grandes dificuldades para lidar com a diferença e para oferecer a essas crianças uma educação compatível com os seus próprios modos de funcionar, se comunicar e se comportar.

O pensamento de Canguilhem nos lembra da dificuldade de traçar linhas claras quando se trata de conceituar o normal e o patológico, mas a escola se encarrega de demarcar os limites de tolerância ao que se afasta do ideal, dos conjuntos homogêneos de crianças capazes de permanecerem várias horas realizando atividades supervisionadas por um professor, que deve ensinar conhecimentos e modos de comportamento necessários para que elas progridam conforme as previsões do sistema. É claro que a extensão da escolaridade a todos os grupos sociais, a heterogeneidade socioeconômica e cultural e a presença de crianças que aprendem em ritmos diferentes por uma variedade de razões afastam a escola contemporânea daquela cuja origem Foucault recupera quando rememora as mudanças ocorridas na história até chegar ao ensino seriado.

Ainda assim, a consideração de elementos da história da instituição educativa e do seu funcionamento colabora para a compreensão das 
tensões envolvidas na escolarização de crianças que são muitas vezes refratárias à persuasão pela aplicação das técnicas disciplinadoras, não obedecem, se recusam a ocupar o lugar que lhes é reservado, não realizam as atividades, não atendem às solicitações e, consequentemente, não podem ser controladas pelo sistema de recompensas e sanções descrito por Foucault.

É preciso acrescentar que na concepção dialética e dinâmica da vida social e do desenvolvimento humano, a escola, cujos traços disciplinadores e normativos foram aqui destacados, também contém os elementos de superação, resistência e um grande potencial para promover, por meio da convivência, da interação e da aquisição de conhecimento, o desenvolvimento das crianças e a formação de outros tipos de subjetividade, não necessariamente submissos ou disciplinados nos termos de Foucault.

A compreensão dos difíceis termos da relação entre as crianças com TEA e a escola motiva a reflexão sobre os caminhos possíveis para uma educação formal que assuma o desafio de educar e não de disciplinar. Vigotski (1997), ao contestar as visões corretivas e normalizadoras, centradas no defeito, aporta elementos para questionar algumas das práticas mais comuns relacionadas à criança com TEA.

Muito frequentemente, o diagnóstico psiquiátrico, independente do lugar em que a criança se situa no continuum que envolve o uso da linguagem, os modos de comunicação, a presença de interesses restritos, problemas de aprendizagem, agitação, impulsividade e pouca flexibilidade (APA, 2014), é acompanhado da prescrição de terapias comportamentais, como Applied Behavioral Analysis - ABA (BAER; WOLF; RISLEY, 1968; LOOVAS, 1987) e Treatment and Education of Autistic and Communication Handicapped Children - TEACCH (MESIBOV; SHEA; SCHOPLER, 2005). Ambas as técnicas se baseiam nos princípios da psicologia comportamental. A primeira aplica a Análise do Comportamento ao estudo da conduta da criança para propor objetivos, atividades e recompensas graduadas de acordo com as metas alcançadas. A ideia é conduzir o indivíduo, por meio do reforço positivo a realizar as atividades previstas no contexto clínico, com vistas a que esses comportamentos se generalizem nos demais ambientes de que a criança participa, incluída a escola.

O TEACCH foi desenhado como método educacional e parte do conhecimento sobre as formas de percepção e competências de linguagem, cognitivas e sociais da criança. A partir desse conhecimento propõe atividades em ambiente estruturado, de caráter previsível, que alterna tarefas e descanso, dosando o tempo de atividade de acordo com as condições de atenção da criança. O método se baseia também na proposta de desafios graduais para promover a consecução das metas traçadas, dando destaque às diferentes formas de comunicação e à linguagem (MESIBOV; SHEA; SCHOPLER, 2005).

A predominância dessas visões e o viés normalizador, corretivo e controlador compartilhado pela psiquiatria e pela psicologia comportamental, tão amplamente criticado por Canguilhem e Foucault explicam por que, apesar de existirem outras abordagens clínicas e educacionais, domina a concepção de que os métodos comportamentais são os únicos eficazes na educação de crianças com TEA.

\section{Exemplos da prática escolar}

A opção pela abordagem histórico-cultural, por outro lado, implica a preferência por práticas que considerem as formas de colaboração estabelecidas na interação. Vigotski afirma, em texto escrito em 1931, que as formas coletivas de colaboração são anteriores ao comportamento individual (talvez hoje disséssemos autônomo) e que este se origina na atividade colaborativa e coletiva. Para além da tese que remete à lei do aparecimento duplo das funções psíquicas superiores (uma vez nas relações interindividuais e outra na própria psique do sujeito), essa ideia leva a privilegiar a formação de grupos heterogêneos e a promover a convivência entre crianças com diferentes níveis de desenvolvimento. Entende-se, assim, que a interação com o coletivo permitirá a apropriação e a construção das funções intrapsicológicas (VIGOTSKI, 1997).

$\mathrm{Na}$ década de 1930, Vigotski propunha, seguindo o espírito da época, a segregação das crianças com deficiência e daquelas "dificilmente educáveis”. Mas, a segregação, do seu ponto de vista, seria útil para ensinar às crianças os recursos de linguagem e de aprendizagem cuja apropriação requereria um foco individualizado. Também é preciso levar em conta que mesmo concebendo a educação da criança com deficiência em um contexto segregado (porque especializado), Vigotski defendia a necessidade da convivência entre os diferentes e, especialmente, entre crianças com deficiência e crianças e adultos sem deficiência.

No mesmo texto, ele afirma: "Assim como é praticamente inútil lutar contra o defeito e suas consequências diretas é, ao contrário, legítima, 
frutífera e promissora a luta contra as dificuldades na atividade coletiva". (VIGOTSKI, 1997, p. 223).

A frase inspira a pensar na importância de aceitar a criança e, sempre que possível, os seus comportamentos diferentes, e de promover a sua participação na atividade coletiva, independente das suas dificuldades. O fundamento dessa postura reside na ideia de que a subjetividade se constitui na interação com o outro, mas essa interação não pode ser concebida de forma unilateral, como o modo correto ou socialmente convencionado de se estabelecer relações. É preciso reconhecer e aceitar outras possibilidades ou condições de funcionamento. $\mathrm{Na}$ prática docente, isso significa que o professor poderá lançar mão de um conjunto de princípios que resultarão em estratégias a serem criadas para cada situação.

Estudos recentes, no nosso meio, abordam essas dimensões e reivindicam os conceitos Vigotskianos nas suas análises. Elas mostram a importância de conceitos como os de mediação e interação e o foco na linguagem e na comunicação para balizar a prática pedagógica (SANTOS; OLIVEIRA, 2013). Outro trabalho de Oliveira et al. (2016) aponta para a necessidade de não estigmatizar os alunos como um dos passos na direção da inclusão. As autoras notam também a frequente infantilização dos alunos com TEA e destacam o cuidado necessário para não incorrer em práticas que impeçam a criança de aprender e participar. O trabalho de Martins e Góes (2013), por sua vez, se debruça sobre o papel do brincar no desenvolvimento da criança e analisa as possibilidades de atribuição de sentido, questionando a ideia de que essas crianças preferem objetos a pessoas. Da mesma forma, Da Silva e Silva (2017) indicam, nas suas elaborações sobre o jogo de papéis, a importância deste para o desenvolvimento do simbolismo e das relações de alteridade.

Ao longo de anos de interlocução com professores do ensino fundamental e com famílias de crianças com TEA recolhemos uma série de relatos que envolvem crianças com diferentes características e personalidades. Eles ilustram as formas de lidar com situações concretas de sala de aula inspiradas nos princípios da perspectiva histórico-cultural. Esses princípios se traduzem em práticas que, mesmo reconhecendo a tensão e a dificuldade de implementação no contexto escolar, implicam a aceitação, o respeito e a valorização da diferença, a flexibilização de normas e regras e a disposição para negociar os termos de participação dos alunos na escola. Seguem alguns exemplos que podem inspirar modos de abordar a criança com TEA na sala de aula: - Uma criança de cinco anos começa a chorar no parque da escola. Embora a criança fale apenas algumas poucas palavras, a professora pergunta se ela sente dor, frio, calor, se precisa ou deseja alguma coisa. A criança aponta para a sua mão e a professora descobre que a criança foi picada por uma formiga. Frequentemente, o choro da criança com TEA é considerado como sintoma da sua condição e não como manifestação de frustração, dor ou sofrimento causado por algum fator externo. Procurar compreender os motivos do comportamento implica reconhecer a existência de um sujeito que sente, elabora e estabelece diferentes tipos de relação com o meio.

- Na segunda série do ensino fundamental, uma criança se refugia atrás do armário sempre que fica agitada ou nervosa ao enfrentar uma tarefa difícil (como quando é a vez dela de ler em voz alta um pequeno trecho de um texto). A professora diz para a criança que ela pode se acalmar e voltar para a sua carteira quando estiver pronta. Depois de alguns minutos, a professora se aproxima da criança $e$ pergunta se ela está pronta. A criança retorna a sua carteira e faz a leitura do texto. A atitude da professora denota o mesmo reconhecimento básico do sujeito que observamos no exemplo anterior e, em decorrência disso, o estabelecimento de relações que implicam o respeito de rituais e rotinas e a sua legitimação enquanto formas de expressão de necessidades, emoções ou sentimentos da criança. $\mathrm{O}$ desfecho do episódio é ilustrativo da potência da estratégia para propiciar a participação da criança na atividade coletiva.

- Na educação infantil, não é permitido levar brinquedos de casa, a não ser no dia combinado, mas a criança não consegue (inicialmente) ficar sem seu objeto preferido. A professora autoriza a criança a chegar à escola com o brinquedo e depois ela pede para guardar o brinquedo até a hora de ir embora. Nessa situação, a professora flexibiliza a regra para permitir que a criança, ao sentir-se aceita e segura, acolha mais facilmente as demandas do ambiente social e incorpore as regras na medida das suas possibilidades.

- No ensino fundamental, as crianças, divididas em pequenos grupos, elaboram cartazes informativos sobre o surto do vírus Zica. A criança em questão se recusa a participar da atividade. A professora, sabendo que a criança tem habilidade especial para o desenho, propõe que ela colabore desenhando o motivo escolhido por um dos grupos. Uma vez inserida no grupo, a criança acaba participando de 
outras etapas da elaboração do cartaz. No episódio, chama à atenção a valorização das qualidades e habilidades da criança enquanto pontos de partida para propiciar um deslocamento na direção da aquisição de novos conhecimentos. A professora partiu do conhecimento sobre seu aluno para propiciar um tipo de participação que a criança pudesse aceitar, apostando na mediação do grupo para promover outras formas de participação, partilha e apropriação de conhecimentos.

\section{Considerações finais}

Ao destacar a necessidade de analisar as condições de existência e a história do desenvolvimento da criança no contexto familiar, institucional e social, Vigotski nos insta a procurar as causas das dificuldades e a origem dos problemas e dos comportamentos que hoje seriam facilmente identificados com sintomas de várias condições. Segundo os critérios diagnósticos atuais (APA, 2014), essas condições podem inclusive ser adicionadas umas às outras (TEA, TDAH, Transtorno de aprendizagem, Transtorno de comportamento, Transtorno de ansiedade, Deficiência intelectual, entre outras). $\mathrm{O}$ aumento do número de condições e da frequência com que as crianças são encaminhadas a serviços de saúde para diagnóstico e tratamento é comentada por diversos pesquisadores que assumem posições críticas. Referindo-se especificamente ao aluno com TEA, Orrú e Silva afirmam:

A classificação, imposta pelo diagnóstico, retira o estudante da participação na processualidade de sua constituição. Por meio desse efeito iatrogênico, ele é deslocado para a sombra das características diagnósticas e permanece vivendo no que hoje vem se denominando espectro do autismo. A identidade do estudante é ocultada imediatamente quando o médico assina o laudo de autista, pois a síndrome e seu quadro sintomático se materializam nesse indivíduo. (ORRÚ; SILVA, 2015, p. 63)

Os pressupostos da Teoria HistóricoCultural do Desenvolvimento oferecem instrumentos de análise que conduzem a uma postura crítica em relação à abordagem medicalizadora. Vigotski insiste na defesa de um olhar que considere o sujeito para além da falta ou do déficit, - qualquer que seja ele - um olhar atento à personalidade, às necessidades de comunicação e linguagem e ao desenvolvimento das funções psíquicas superiores mais sofisticadas como a atenção voluntária, a memória lógica, o pensamento abstrato, a formação de conceitos e do livre-arbítrio. "Onde não é possível avançar no desenvolvimento orgânico, abre-se um caminho sem limites para o desenvolvimento cultural". (VIGOTSKI, 2011, p. 869).

Essas ideias mostraram-se alinhadas às expostas por Canguilhem. As suas elaborações apresentam renovada potência para defender a observação cuidadosa, não do comportamento infantil como entidade independente, mas principalmente, das condições em que ele ocorre na família, na escola e em outros ambientes sociais. Ainda, as suas reflexões assinalam a necessidade de caracterizar as instituições e seu funcionamento, assim como de entender criticamente o papel das normas que estas preconizam e suas implicações na constituição dos sujeitos. O trabalho desenvolvido por Foucault, nesse sentido, proporciona ferramentas conceituais que permitem identificar e analisar esses processos nas diferentes instituições em que se concretiza a vida social.

A compreensão sobre a dinâmica da instituição escolar implica a tomada de consciência em relação às condições estruturalmente tensas que atravessam o campo da educação. Por outro lado, a análise dessas condições nos inspira a buscar subsídios teórico-metodológicos condizentes com as nossas convicções. Essas não são tarefas triviais no contexto de uma estrutura pautada nas demandas de desempenho, nas avaliações e na normatividade baseada na disciplina que visa à eficiência e à homogeneidade, a despeito das diferenças de toda índole (física, psicológica, cultural, social) que distinguem as crianças.

Por isso, defender práticas que propiciem a constituição de sujeitos conscientes de si mesmos, dos outros e do ambiente, que auxiliem os alunos no seu desenvolvimento, entendido como função da participação na vida social, implica assumir uma posição política que permeia as perguntas e as análises que fazemos, assim como as decisões pedagógicas que norteiam a prática.

Inquirir sobre as razões do comportamento do aluno e não assumir simplesmente que o autismo é a causa de todas as dificuldades denota uma atitude não preconceituosa e questionadora, além de sensibilidade em relação aos múltiplos fatores que podem incidir no comportamento e na aprendizagem das crianças. Indagar sobre as causas do comportamento ou das relações da criança com o meio social e com o conhecimento permite a identificação dos elementos da cultura que impactam 
esses comportamentos e relações. Esses posicionamentos implicam uma visão contraposta àquela que defende a adoção de métodos prescritos unicamente para crianças com TEA, independentemente das suas particularidades, personalidades e condições do contexto.

Assim, quando o professor/professora flexibiliza uma regra em uma situação para fazer questão dela em outra, quando admite que a criança abandone uma atividade em um momento para incentiva-la a retomar o trabalho no seguinte ou quando ele/a organiza a atividade coletiva de modo que a criança com TEA se sinta instada a participar, podemos reconhecer os conceitos e tendências já elencados, os quais operam propiciando a ponderação dos diferentes elementos em jogo, assim como a consideração da tensão constitutiva que atravessa a educação.

O leitor atento, nessa altura dirá: mas não é isso que fazemos com todas as crianças? Pois é, é disso mesmo que se trata...

\section{Nota}

1 Devido às diferenças de grafia nas traduções, optou-se, no corpo do texto, pela grafia Vigotski. Nas referências foram mantidas as grafias originais dos tradutores.

\section{Referências}

\section{AMERICAN PSYCHIATRIC ASSOCIATION. Manual Diagnóstico e Estatístico de Transtornos Mentais - DSM-5. Porto Alegre: Artmed, 2014.}

BAER, D. M.; WOLF, M. M.; RISLEY, T. R. Some current dimensions of applied behavior analysis. Journal of Applied Behavior Analysis, v. 1, n. 1, p. 91-97, 1968. Disponível em:

https://onlinelibrary.wiley.com/doi/abs/10.1901/jaba .1968.1-91. Acesso em: 12 de junho de 2018.

BOURDIEU, P. A escola conservadora: as desigualdades frente à escola e à cultura. In: NOGUEIRA, M.; CATANI, A. (org). Escritos de Educação. Petrópolis: Vozes, 1998. p. 39-64.

BOURDIEU, P. O poder simbólico. Inserir edição. Rio de Janeiro: Bertrand Brasil, 2002.

CANGUILHEM, G. O normal e o patológico.
Inserir edição. Rio de Janeiro: Editora Forense Universitária, 2009.

DA SILVA, M. A.; SILVA, D. N. H. O jogo de papéis e a criança com autismo na perspectiva histórico-cultural. Psicol. estud., Maringá, v. 22, n. 3, p. 485-496, jul./set. 2017. Disponível em: http://periodicos.uem.br/ojs/index.php/PsicolEstud/a rticle/view/35745. Acesso em: 12 de junho de 2018.

DAINEZ, D. Constituição humana, deficiência e educação: problematizando o conceito de compensação na perspectiva histórico-cultural. 2014. 132 f. Tese (Doutorado em Educação) Faculdade de Educação. Universidade Estadual de Campinas, Campinas, 2014.

DAINEZ, D.; SMOLKA, A. L. B. VygotskianInspired Research on the Developmental Implications of Organic Impairment. Mind, Culture, and Activity, 2016, 24:4, 324-337. Disponível em: https://www.tandfonline.com/doi/abs/10.1080/1074 9039.2016.1181183? journalCode=hmca20. Acesso em: 1 de junho de 2018.

FOUCAULT, M. A história da loucura na idade clássica. Inserir edição. São Paulo: Perspectiva, 1997.

Doença mental e psicologia. Inserir edição. Rio de Janeiro: tempo brasileiro, 1988.

Em defesa da sociedade. Curso dado no College de France (1975-1976). Inserir edição. São Paulo: Martins Fontes, 2005.

Vigiar e Punir: nascimento da prisão. Inserir edição. Petrópolis: Vozes, 1987.

LOVAAS, O. I. Behavioral Treatment and Normal Educational and Intellectual Functioning in Young Autistic Children. Journal of Consulting and Clinical Psychology, v. 55, n. 1, p. 3-9, 1987. Disponível em: http://www.beca-aba.com/articlesand-forms/lovaas-1987.pdf. Acesso em: 12 de agosto de 2017.

MARTINS, A. D. F.; GÓES, M. C. R. Um estudo sobre o brincar de crianças autistas na perspectiva histórico-cultural. Revista Semestral da Associação Brasileira de Psicologia Escolar e Educacional, SP. Volume 17, Número 1, Janeiro/Junho de 2013: 2534. Disponível em: 
http://www.scielo.br/pdf/pee/v17n1/a03v17n1.pdf. Acesso em: 10 de maio de 2018.

MESIBOV, G. B.; SHEA, V.; SCHOPLER, E. (with Adams, L.; Burgess, S.; Chapman, S. M.; Merkler, E.; Mosconi, M.; Tanner, C. \& Van Bourgondien, M.E.). The TEACCH approach to autism spectrum disorders. New York: Kluwer Academic/Plenum, 2005.

OLIVEIRA, I. M.; SANTOS, E. C. dos; CHIOTE, F de A. B.; PINTO, A. K. P. A inclusão de um jovem com autismo no ensino médio, na perspectiva de seus colegas de turma. In: VICTOR, S. L.; OLIVEIRA, I. M. (Org.) Educação Especial na perspectiva da Educação Inclusiva: concepções e práticas educativas. Marília: ABPEE, 2016. p. 63-83.

ORRÚ, S. E.; SILVA, V. A escola e a maré iatrogênica do diagnóstico no trabalho junto a estudantes com autismo. Ensino Em Re-Vista, v.22, n.1, p. 59-66, jan./jun. 2015. Disponível em: http://www.seer.ufu.br/index.php/emrevista/article/v iew/30725/16785. Acesso em: 14 de junho de 2018.

ROUDINESCO, E. Filósofos na tormenta. Inserir edição. Rio de Janeiro: Zahar, 2007.

SANTOS, E. C.; OLIVEIRA, I. M. Trabalho

Pedagógico e autismo: desafios e possibilidades.
Revista FACEVV, v. 10, p. 46-58, 2013. Disponível em: http://atividadeparaeducacaoespecial.com/wpcontent/uploads/2014/07/TRABALHO-

PEDAG\%C3\%93GICO-E-AUTISMO-DESAFIOSE-POSSIBLIDADES.pdf. Acesso em: 14 de junho de 2018.

VIGOTSKI, L. S. A defectologia e o estudo do desenvolvimento e da educação da criança anormal. Educação e Pesquisa, São Paulo, v. 37, n. 4, p. 861870, dez. 2011. Disponível em:

$<$ http://www.scielo.br/scielo.php?script=sci_arttext \&pid=S1517-

$97022011000400012 \& \operatorname{lng}=e n \& n r m=i s o>$. Acesso em 25 de junho de 2018.

VYGOTSKI, L. S. La infancia difícil. In: Fundamentos de defectología. Obras Escogidas, Vol. V. Madrid, España: Visor Distribuciones, 1997. p. 153-167.

VYGOTSKI, L. S. El desarrollo del niño difícil y su estudio. In: Fundamentos de defectología. Obras Escogidas, Vol. V. Madrid, España: Visor Distribuciones, 1997. p. 191-196.

VYGOTSKI, L. S. La colectividad como factor de desarrollo del niño deficiente. In: Fundamentos de defectología. Obras Escogidas, Vol. V. Madrid, España: Visor Distribuciones, 1997. p. 213-234.

\section{Sobre a autora}

Adriana Lia Friszman de Laplane é pedagoga, mestre e doutora em Educação e docente do curso de Fonoaudiologia da Faculdade de Ciências Médicas da Universidade Estadual de Campinas. Atua também no programa de pós-graduação Saúde, Interdisciplinaridade e Reabilitação, da mesma Faculdade. Estuda os processos de desenvolvimento da criança e pesquisa políticas e práticas de educação, com foco na inclusão de pessoas com deficiência.

Recebido em julho de 2018.

Aprovado em outubro de 2018. 